\title{
Genetic inheritance of susceptibility to tinea imbricata
}

\author{
DAVID RAVINE*, KEVEN J TURNER*, AND MICHAEL P ALPERS $\dagger$ \\ From the *Department of Microbiology, University of Western Australia, and \\ $\dagger$ †apua New Guinea Institute of Medical Research, Goroka, Papua New Guinea
}

SUMMARY Segregation analysis on 228 family pedigrees collected from a Papua New Guinear population provided data that strongly supported a previous report of an autosomal recessive pattern of inheritance of a susceptibility to tinea imbricata. The frequency of the susceptibility genè within the population studied was found to be $0.49 \pm 0.04$, calculated on the assumption of an autosomal recessive mode of inheritance. However, in spite of the strong evidence in support o $\hat{\omega}^{\circ}$ autosomal recessive inheritance, the possibility of autosomal dominant inheritance with reduced penetrance cannot be excluded.

Tinea imbricata is a superficial skin fungal disease caused by Trichophyton concentricum. ${ }^{1}$ It is found predominantly in the tropics extending from the Indian subcontinent eastwards through south-east Asia, north to southern China, and south through Indonesia and Papua New Guinea to the South Pacific islands. It is also found in limited areas in South America, particularly Brazil. ${ }^{2}$

It is of interest that, although the disease is found extensively throughout the tropics, it is absent from Africa $^{3}$ and northern Australia. ${ }^{4}$ If a tropical environment is favourable for the spread of $T$ concentricum, it is reasonable to conclude from the absence of tinea imbricata in certain tropical areas that additional factors are important for the disease to occur. The observations of Dey and Marplestone, ${ }^{5}$ Polunin, ${ }^{6}$ and Reid ${ }^{7}$ that the prevalence of tinea imbricata was much higher in some races than in others living in the same country under closely related environmental circumstances highlight the presence of racial characteristics in determining susceptibility to the disease. These reported racial differences in prevalence may be the result of ethnically induced environmental differences between the various racial groups living in close proximity to each other. However, the marked differences may also result from a differing incidence of an inherited susceptibility within these genetically distinct groups.

Schofield $e t a l^{8}$ reported on family studies within a Melanesian population which suggested that genetic factors may play a part in determining whether or not a person became chronically infected. More recently, Serjeantson and Lawrence ${ }^{9}$ have described Received for publication 8 October 1979 a familial distribution of chronic Trichophyto⿸厂 concentricum infection consistent with a recessively inherited susceptibility controlled by genes at $8_{0}^{\circ}$ single autosomal locus. These authors noted thaP while a common environment, particularly in the case of infectious disease, may lead to a highe disease incidence in relatives than in the generaf population, the frequency of tinea imbricata in families very closely approximated the expecte $\Phi$ values obtained by segregation analysis testing for autosomal recessiveness. However, the data were obtained by noting only current tinea imbricata infection within families and sibs living in a tine宩 imbricata endemic area. No historical information on previous infection was collected although the population was stated to be untreated. A degree of uncertainty is cast on these results when the pape? of Schofield $e t a l^{8}$ is considered. They reported thas many infected males became free of the disease while working away from the village and a smalt number of these did not become reinfected on retura to the village. Some children living in these endemio areas spontaneously lost their infection and late remained free from it, despite their remaining in $\$$ susceptible environment. These additional factors? together with the previously mentioned smant proportion of people who first became infected i⿱⿱一⿱㇒⿴囗⿱一一夊厶. adult life, were not taken into account by Serjeantso and Lawrence. ${ }^{9}$ It raises the possibility that theif conclusions, based on data obtained from a relativel small number of families and sibships, may not be valid if these additional historical factors are cono sidered.

Because of this uncertainty about the reporte 
mode of inheritance of susceptibility to the disease, family pedigrees were collected from a population where the disease prevalence was known to be high. These pedigrees were then subjected to segregation analysis testing for autosomal recessive and other possible modes of inheritance.

\section{Materials and methods}

The populations studied were located in seven villages in the Gogol Valley. The valley is located in the northern lowland area of Papua New Guinea. Five language groups were represented within the villages included in the study. One language was Austronesian while the other four were nonAustronesian in origin. There was no significant difference in either the prevalence or incidence rates of the disease within the different linguistic groups represented in the population. Because of the patrilineal system of land tenure practised in this area and the consequent flow of women into and out of clans, enquiry was only conducted into the pedigrees of the husbands. Enquiry was not made into the pedigrees of female spouses. Instead, the name of the wife's village of origin was recorded and if it was a village included in the study, the name of her father and his clan was recorded for future reference. This simplified the collection of pedigrees while not preventing complete ascertainment of pedigrees from the total population of the seven villages.

Enquiry was continued back into previous generations and their offspring until the knowledge of the informant group was exhausted. For each subject recorded in the pedigree, information was sought as to whether or not they had ever had tinea imbricata and, if they had, how old they were when first affected and the approximate percentage of skin infected. In addition, they were asked whether the disease had ever resolved and, if it had, what they thought had caused it to resolve and how old they were when it disappeared. If a person in the pedigree had died, then in addition to the questions relating to tinea imbricata infection questions were also asked about the age at death and the possible cause of death.

The pedigrees were then analysed in the following way. Infants less than 2 years of age were excluded from the genetic analysis since the cumulative rate of infection increased sharply over the first 2 to 3 years, suggesting the presence of many young susceptible infants who were yet to become infected (fig 1). Subjects older than 2 years, who gave a history of being persistently infected with tinea imbricata, were recorded as being susceptible. Those

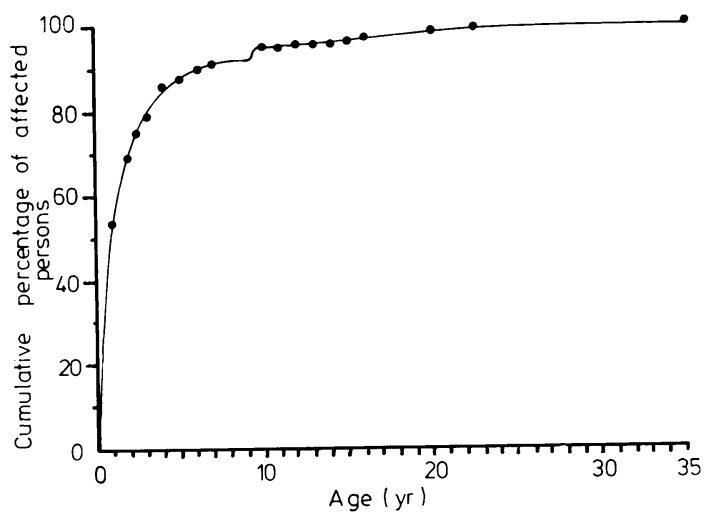

FIG 1 Cumulative frequency graph of age of onset of tinea imbricata.

who had a spontaneous and permanent cure from infection in childhood were regarded as not being susceptible. Anyone with a history of tinea imbricata infection in adulthood was regarded as susceptible.

The pedigrees were examined initially for evidence of sex linked inheritance. Tests were then made for randomness of mating and autosomal dominant inheritance using the $\chi^{2}$ test. This was followed by the application of an a priori segregation analysis, ${ }^{10}$ testing for autosomal recessive inheritance.

Gene frequencies, assuming autosomal recessive inheritance, were estimated from the frequency of homozygotes using the Hardy-Weinberg equilibrium. The standard error of this method of estimation, together with the $95 \%$ confidence limits, were calculated according to the method described by Emery. ${ }^{11}$

\section{Results}

MULTIFACTORIAL INHERITANCE

Inspection of the pedigrees failed to reveal any evidence of multifactorial inheritance. The incidence of the disease did not decline in second and third degree relatives as would be expected if multifactorial inheritance was present.

\section{SEX LINKED INHERITANCE}

No evidence was found for sex linked inheritance, as the disease incidence did not alter significantly between the sexes (table 1). In families where only one spouse had tinea imbricata a further comparison was made between the number of affected male and female offspring grouped according to whether their mother or father was affected.

In both groups of families, the observed number of affected male and female offspring did not differ 
TABLE 1 Incidence of tinea imbricata infections in males and females

\begin{tabular}{|c|c|c|c|}
\hline & Male & Female & Total \\
\hline $\begin{array}{l}\text { No history of infection with } \\
\text { tinea imbricata } \\
\text { History of infection with tinea }\end{array}$ & 287 & 286 & 575 \\
\hline $\begin{array}{l}\text { imbricata } \\
\text { Total }\end{array}$ & $\begin{array}{l}109 \\
398\end{array}$ & $\begin{array}{r}88 \\
374\end{array}$ & $\begin{array}{l}197 \\
772\end{array}$ \\
\hline
\end{tabular}

$\chi^{2}=1 \cdot 3134, \mathrm{df}=1, \mathrm{p}=0.2518$

significantly from the expected, assuming that sex did not influence the disease incidence. It was concluded that there is no evidence of $\mathrm{X}$ linked recessive inheritance, where the incidence of infection in males would be expected to be significantly higher than in females. Additionally, there is no evidence of $\mathbf{X}$ linked dominant inheritance where affected males would be expected to transmit the trait to all their daughters and to none of their sons.

\section{A UTOSOMAL DOMINANT INHERITANCE}

The pedigrees were then tested for autosomal dominant inheritance (table 2). The number of offspring in families in which there was only one parent affected was compared with the expected number, calculated assuming an autosomal dominant mode of inheritance. The observed values differed markedly from the expected values producing the large $\chi^{2}$ value of $49 \cdot 2$. At $1 \mathrm{df}$ the probability of this occurring by chance alone was less than 0.001 and therefore the mode of inheritance is unlikely to be autosomal dominant if there is complete penetrance of the gene. However, an autosomal dominant mode of inheritance is still a possibility if incomplete penetrance is present. Fig 2 shows a family pedigree which displays a possible autosomal dominant mode of inheritance.

\section{AUTOSOMAL RECESSIVE INHERITANCE}

Finally, the pedigrees were subjected to segregation analysis, testing for autosomal recessive inheritance. However, before performing the segregation analysis, randomness of mating was tested for, because this is

TABLE 2 Test for autosomal dominant inheritance

\begin{tabular}{lccl}
\hline \multicolumn{3}{l}{ Offspring of affected parent with } & a healthy spouse \\
\hline Offspring & Normal & Affected & Total \\
\hline Observed (O) & 189 & 75 & 264 \\
Expected (E) & 132 & 132 & 264 \\
(O-E) 2 & 3249 & 3249 & \\
(O-E) & & 24.61 & $\chi^{2}=49.22$ \\
\hline $\mathrm{E}$ & 24.61 & & \\
df $=1, \mathrm{p}<0.001$. & & &
\end{tabular}

a necessary condition for the Hardy-WeinbergD equilibrium upon which the analysis is dependent: Among tinea imbricata susceptible adults from $\mathrm{f}_{\mathrm{i}}$ and $\overrightarrow{\overrightarrow{\mathrm{s}}}$ $\mathrm{p}_{\mathrm{i}}$ generations, a larger number than expected were found to be unmarried (table 3). However, the difference in this population sample failed to reactip significance. When the mating pattern of tineap imbricata susceptible and resistant subjects waș tabulated, the observed numbers of the four possible marriage combinations were found to approximate closely the expected numbers (table 4). Therefore, $\vec{E}$ there was no indication for introducing an inbreed ing coefficient into the segregation analysis.

Gene frequencies assuming recessive inheritancto were then calculated, using the Hardy-Weinberg $\vec{v}$ principle, both for adults producing offspring included in the segregation analysis and for the off $\frac{\mathrm{N}}{\mathrm{N}}$ spring in the analysis.

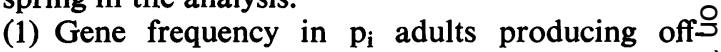
spring included in the analysis $=0.4889$ 0.0406 ( $95 \%$ confidence limits).

(2) Gene frequency in $f_{i}$ offspring included in the्ठ segregation analysis $=\mathbf{0 . 4 6 9 2}$.

In table 5 , the observed and expected number of families with affected children, and of total affecteco children, are tabulated for 228 families within the pedigrees about whom information had been obtained first hand. This excluded families that had

TABLE 3 Randomness of mating. Number of married and unmarried tinea imbricata susceptible and immune and $f_{i}$ and $p_{i}$ generation adults older than 21 years.

\begin{tabular}{lllc}
\hline & Married & Unmarried & Total \\
\hline Tinea imbricata & & & \\
$\quad$ immune + & 227 & 33 & 260 \\
Tinea imbricata & 79 & 20 & 99 \\
$\quad$ susceptible \pm & 306 & 53 & 359 \\
Total & & &
\end{tabular}

$\chi^{2}=3.24, \mathrm{df}=1,0.1>p>0.05$ (not significant).

TABLE 4 Mating pattern of tinea imbricata susceptible and immune subjects within the population of all married adults recorded in the pedigrees in whom the informants were certain of the presence or absence of infection

\begin{tabular}{|c|c|c|c|c|}
\hline & & $\begin{array}{l}\text { Tinea imbricata } \\
\text { immune } \\
\text { males }\end{array}$ & $\begin{array}{l}\text { Tinea imbricata } \\
\text { susceptible } \\
\text { males }\end{array}$ & Total \\
\hline $\begin{array}{l}\text { Tinea imbricata } \\
\text { resistant } \\
\text { females }\end{array}$ & $\begin{array}{l}\text { Observed } \\
\text { Expected }\end{array}$ & $\begin{array}{l}294 \\
293.9\end{array}$ & $\begin{array}{l}72 \\
72 \cdot 1\end{array}$ & 366 \\
\hline $\begin{array}{l}\text { Tinea imbricata } \\
\text { susceptible } \\
\text { females }\end{array}$ & $\begin{array}{l}\text { Observed } \\
\text { Expected } \\
\text { Total }\end{array}$ & $\begin{array}{c}81 \\
81 \cdot 1 \\
375\end{array}$ & $\begin{array}{l}20 \\
19 \cdot 9 \\
92\end{array}$ & $\begin{array}{l}101 \\
467\end{array}$ \\
\hline
\end{tabular}




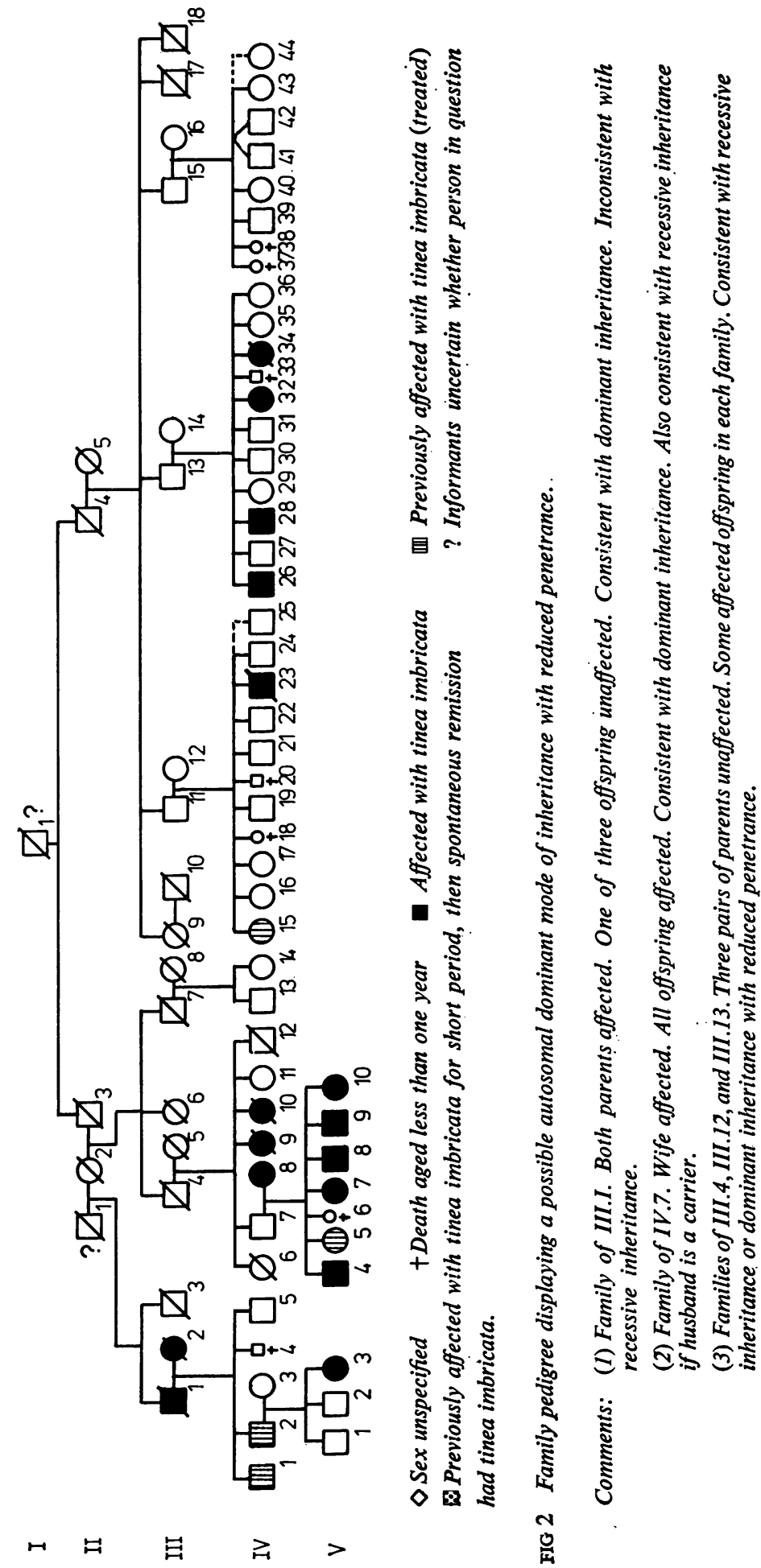


TABLE 5 Family analysis assuming recessivity of susceptibility to tinea imbricata

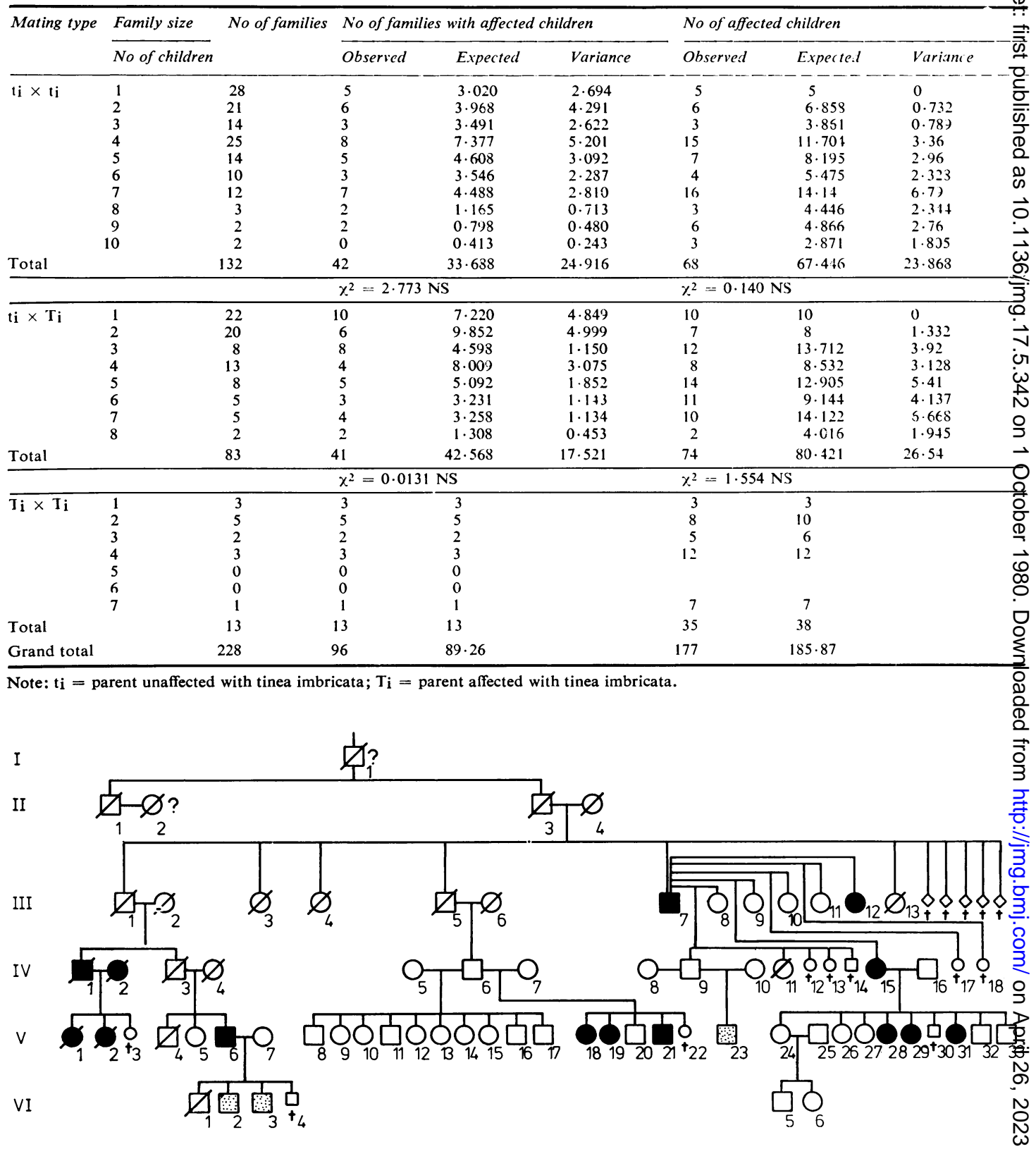

FIG 3 Pedigrees consistent with autosomal recessive mode of inheritance with a high gene frequency. (Symbols as for fig 20 )

Comments. (I) Family of IV.7. Both parents unaffected. Some offspring affected. Consistent with autosomal recessive inheritance.

(2) Family of IV 16 . One parent affected. Three of eight live children affected. Consistent with both autosomal recessive and autosomal dominant inheritance.

(3) Family of $I V \cdot 1$. Both parents affected. Two of the three children affected. Third child died aged less than one year. Consistent with both autosomal recessive and dominant inheritance. 
died out or were located in another village not included in this study. The subjects without tinea imbricata have been denoted $t_{i}$, while those with the disease are denoted $T_{i}$. In 132 productive matings where both parents were unaffected, 67.4 affected children were expected, if the hypothesis of recessivity is correct, and 68 were seen. Of these 132 families, 33.7 were expected to have at least one child with tinea imbricata while 42 were observed.

In 83 matings of type $t_{i} \times T_{i}, 80.4$ affected children were expected and 74 were seen. Of these 83 families, $42 \cdot 6$ were expected to have at least one child with tinea imbricata, while 41 were observed. There is no significant difference between the observed and expected values in any of these groups.

In 13 matings productive of children where both parents had the disease, 38 affected children were expected while 35 were observed. Of these 13 families, 13 were expected to have all children affected and 10 were seen. These latter observed results, although closely approximating the expected, are not in full concordance with the hypothesis of recessivity.

These data, with the exception of the three unaffected offspring from mating type $T_{i} \times T_{i}$ (both parents affected with tinea imbricata), is in accordance with the hypothesis of a predisposition to tinea imbricata controlled by a recessive gene or genes segregating at a single autosomal locus. Fig 3 shows a typical family pedigree which is consistent with an autosomal recessive mode of inheritance.

\section{Discussion}

Analysis of the family pedigrees produced results that strongly supported the hypothesis proposed by Serjeantson and Lawrence ${ }^{9}$ of a recessively inherited susceptibility to tinea imbricata controlled by gene(s) at a single autosomal locus. In addition they place the hypothesis on a firmer basis because of the larger sample of families included in the analysis and the consideration that was made of previous tinea imbricata infections.

In support of a genetically determined susceptibility to tinea imbricata was the absence of any evidence of concordance of tinea imbricata in married couples, in spite of the evidence for disease transmission occurring by close assoziation and direct contact with affected people.

The test for autosomal dominant inheritance showed that this mode of inheritance was unlikely. However, it cannot be excluded because of the possibility of the presence of incomplete penetrance.

Evidence for a recessively inherited susceptibility to tinea imbricata was provided by the results of an a priori segregation analysis testing for autosomal recessive inheritance. The observed proportions of affected offspring and families with affected offspring from parents of the different mating types $\left(t_{i} \times t_{i}\right.$, $\left.t_{i} \times T_{i}, T_{i} \times T_{i}\right)$ were not significantly different from the expected proportions calculated in the segregation analysis, assuming the autosomal recessive hypothesis to be correct. It could be anticipated nevertheless that all offspring from the $T_{i} \times T_{i}$ mating type would show disease, yet of those families 35 affected children were observed, whereas 38 were expected. There are at least three potential factors which could contribute towards this difference of observed vs affected: the age of the child, the infectivity of the disease, and illegitimacy. While infants less than 2 years of age were excluded from the genetic analysis, the likelihood exists from fig 1 that a few older children who were susceptible to later development of the disease may have been designated tinea imbricata resistant. It is not clear how much effect this possible underscoring of the numbers of affected children would have influenced the results of genetic analysis. The assumption has been made in calculation of the inheritance pattern that all susceptible subjects had equal exposure to the causative fungus and that the chance and rate of infectivity of such subjects was constant. However, it is not possible to monitor this aspect without active experimental infection, hence it remains conjectural that some unaffected subjects might in fact have been susceptible. The third factor, that of limited illegitimacy, remains a possibility, but no evidence was found in this survey to support such a proposal.

Harper ${ }^{12}$ points out that the existence of Mendelian inheritance does not exclude the operation of important environmental factors influencing the expression of transmission of the disease. This is clearly obvious in the case of tinea imbricata where the presence of the fungus Trichophyton concentricum is necessary for expression of the susceptibility. However, Harper was discussing the problems of identifying diseases thought to have a Mendelian inheritance but which in fact result from a transmissable agent such as a slow virus. In view of the lack of evidence in support of multifactorial inheritance and the close approximation of the pedigrees to a Mendelian recessive pattern of inheritance, it seems unlikely that the susceptibility to tinea imbricata is an expression of some other transmissable agent.

The gene frequency of the recessive trait in this population is unusually high $(0.4889 \pm 0.0406,95 \%$ confidence limits) raising the possibility of the existence of directional or stabilising selection for the gene. A potentially analogous situation is that of 
stabilising selection for the recessive sickle cell gene in Africa. ${ }^{13} \mathrm{~A}$ similar situation may be present in the case of tinea imbricata in this population.

David Ravine was a recipient of the P F Sobotka Undergraduate Scholarship from the Faculty of Medicine, University of Western Australia. The advice and encouragement of Dr Athol Hockey (Princess Margaret Hospital) and Dr G T Nurse (Papua New Guinea Institute of Medical Research) is gratefully acknowledged. The assistance of Dr A Jones, Anatomy Department, University of Western Australia, is gratcfully acknowledged for advice on statistical analysis of the data, as is that of Dr G Mayrhofer, Clinical Immunology Research Unit, Princess Margaret Hospital, for critical appraisal of the manuscript.

\section{References}

1 Castellani A. The growth of the fungus of tinea imbricata on artificial media. J Trop Med Hyg 1910;13:370-2.

2 Rippon JW. Medical mycology. The pathogenic fungi and the pathogenic actinomycetes. Philadelphia: Saunders, 1974.

3 Ajello L. Geographical distribution and prevalence of dermatophytes. Ann NY Acad Sci 1960;89:30-8.
4 Green AC, Kaminski GW. Australian aborigines and their dermatophytes. Australas J Dermatol 1977;18:132-6. 5 Dey NC, Marplestone PA. Tinea imbricata in India
Indian Med Gaz 1942;77:5-6.

6 Polunin I. Tinea imbricata in Malaya. Br J Dermato 1952;64:378-84.

7 ReidS. Skin diseases in Port Moresby, Papua New Guinea Australas J Dermatol 1976;17:1-6.

8 Schofield FD, Parkinson AD, Jeffrey D. Observations on the epidemiology, effects and treatment of tinea imbricata Trans R Soc Trop Med Hyg 1963;57:214-27.

- Serjeantson S, Lawrence C. Autosomal recessive inheritance of susceptibility to tinea imbricata. Lancet 1977 i:13-5.

10 Smith CAB. A test for segregation ratios in family data $\vec{\omega}$ Ann Hum Genet 1956;20:257.

11 Emery AEH. Methodology in medical genetics-an̉ introduction to statistical methods. Edinburgh: Churchiff Livingstone, 1976.

12 Harper PS. Mendelian inheritance or transmissablèr agent? The lesson of Kuru and the Australia antigeniw J Med Genet 1977;14:389-98.

13 Allison AC. Polymorphism and natural selection in human populations. In: Baer AS, ed. Hereditability and society-readings in social genetics. 2nd ed. New York.McMillan, 1964:339-60.

Requests for reprints to Dr D Ravine, Clinica黑 Immunology Research Unit, Princess Margaret. Hospital for Children, Subiaco, Western Australiœo 6008 , Australia. 